\title{
The function of modal judgment and the Kantian gap
}

\author{
Jessica $\operatorname{Leech}^{1}(\mathbb{D}$
}

Received: 13 November 2017 / Accepted: 9 May 2018 / Published online: 25 May 2018

(C) The Author(s) 2018

\begin{abstract}
What is the function of modal judgment? Why do we (need to be able to) make judgments of possibility and necessity? Or are such judgments, in fact, dispensable? This paper introduces and develops an answer to these questions based on Kant's remarks in section 76 of the Critique of Judgment. Here, Kant appears to argue the following: that a capacity to make modal judgments using (categorial) modal concepts is required for a capacity for objective representation, in light of our split cognitive architecture. This split cognitive architecture leaves room for a mismatch between our concepts and intuitions and, Kant argues, that is why we need modal concepts and modal judgments. In this paper, I develop this account of the function of modal judgment and to explore the extent to which it may improve upon contemporary alternatives. I focus on one particularly important challenge for the account: to explain why a distinction between the actual and the possible, rather than merely a distinction between the actual and the non-actual, is required. In order to answer this question, I supplement the account with a particular way of thinking about objectivity.
\end{abstract}

Keywords Actuality · Metaphysical modality · Modal judgment · Objectivity • Possibility · Kant

\section{Introduction}

What is the function of modal judgment? Why do we (need to be able to) make judgments of possibility and necessity? Or are such judgments, in fact, dispensable? My aim in this paper is to introduce and develop a new answer to these questions. Or

$凶$ Jessica Leech

jessica.leech@kcl.ac.uk

1 Department of Philosophy, King's College London, Strand, London WC2R 2LS, UK 
rather, the answer is old-it comes from Kant-but its application to this debate is new.

The proposal is based on Kant's remarks in section 76 of the Critique of Judgment. Here, Kant appears to argue the following: that a capacity to make modal judgments using (categorial) modal concepts is required for our capacity for objective representation, in light of our split cognitive architecture. ${ }^{1}$ Creatures with minds like ours require both intuitions (direct, singular representations) and concepts (mediate, general representations), both the contributions of sensibility (the capacity to be presented with objects in experience) and of thought to have objective representations about the world. This split cognitive architecture leaves room for a mismatch between our concepts and intuitions which could undermine the possibility of objective representation and, Kant argues, that is why we need modal concepts and modal judgments.

My aim in this paper is not to defend this reading of Kant, but to develop this account of the function of modal judgment and explore the extent to which such an account may improve upon the contemporary alternatives. More generally, I aim to give an example of how Kant's philosophy can still make a positive contribution to our philosophical understanding today, namely, how certain aspects of his understanding of objectivity, if defensible, could help us to understand the function of modal judgment.

I shall proceed as follows. First, I separate some different questions that we might be asking, and suggest that one question is particularly interesting: what I call a transcendental question for metaphysical modality. Next, I give a brief overview of extant options. I won't discuss these in extensive detail, or argue that they fail, but I will suggest where a Kantian account might have the potential to improve upon them, or at least provide an interesting alternative. With these preliminaries in place, I turn to the "Kantian gap". In brief: the account has the potential to answer the transcendental question because the function of judgments about possibility and actuality is to make possible objective thought. The account also has the potential to answer the metaphysical modality question, insofar as it concerns a kind of modality that is not merely logical, and which concerns the most general conditions under which we can have objective representations. In my discussion, I focus on one particularly important challenge for the account: to explain why a distinction between the actual and the possible, rather than merely a distinction between the actual and the non-actual, is required. In order to answer this question, I will need to supplement the account with a particular way of thinking about objectivity.

\section{Questions about modal judgment}

When we ask about the function of modal judgment, we need to distinguish different kinds of question that we might be asking. ${ }^{2}$ I am assuming here that "we" are humans, or creatures with human-like cognitive capacities. We are able to have objective thoughts about the world, and perceptions, and engage with the world in all sorts of ways, such as performing actions, and gaining knowledge of the world. What is

\footnotetext{
1 This interpretation is defended and explained at length in Leech (2014).

2 Thank you to John Divers for helpful discussion of these different questions.
} 
most crucial, is that creatures with such cognitive capacities can be mistaken about how the world is, unlike, for example, a divine mind with perfect knowledge. For Kant, that potential for mistake stems-broadly_-from the fact that our capacity for thinking on the one hand, and the way in which we get into touch with the world on the other, can come apart.

First, though, let us pause to consider why we might want to ask questions about the function of modal judgment at all. It may be an interesting issue in its own right, but there is also the potential for deeper significance. One approach to the metaphysics of modality suggests that we should take time to examine the role of our modal judgments, in particular, whether judgments about alethic modality play any legitimate and indispensable role, as an important underpinning to the project of giving an account of modality. For if such judgments were eliminable in favour of, for example, epistemic judgments, we would have no real need for them, and so also we would have no need for an account of modality. Hence, Divers suggests that,

A theory of modality ought to be no more substantial than is required in order to account for the body of modal assertions that we have to make in order to achieve whatever it is that our modalizing achieves for us. (Divers 2010, pp. 190-191)

The worry is that without an account of the function of modal judgment we may overshoot the requirements of our modal theorizing, at best wasting time, at worst developing a theory that misrepresents modality. ${ }^{3}$

One might think that there is a simple answer: the function of modal judgment is to report modal facts. So we can, pretty quickly, assume that there is a realm of modal facts out there to be investigated. However, this is to ignore part of what is so interesting about modality in the first place. One of the peculiarities of modal discourse and judgments is that we cannot take it for granted that they are fact-reporting. Suppose we claim that it is possible that $p$, even though it is not the case that $p$. What kind of fact might that report, given that is it not the case that $p$ ? Similarly, suppose we claim that it is necessary that $q$, over and above its being the case that $q$. Again, what kind of fact might that report beyond the fact that $q ?{ }^{4}$ My point here is not that there are no answers to these questions, but that they seem to be substantive questions to which the answers are not obvious. Hence, it seems reasonable to consider more carefully what role such modal claims are needed to play, before assuming that they are straightforwardly factual..$^{5}$

Moving on, the first kind of question we might ask concerns the kind of role that modal judgment might have for us.

The Practical Question What is the practical use of modal judgments? How would we be worse off if we didn't make them?

\footnotetext{
3 See also Blackburn (1993).

4 My use of 'fact' here is not intended to connote a certain, specific metaphysics of facts, but just the idea that modal judgments may correspond to how things are in the world in a realist way.

5 See also Nolan (2010) for misgivings with this approach.
} 
The Transcendental Question Does modal judgment play a transcendental role-is an ability to make modal judgments a necessary condition of the very possibility of some crucial feature of our cognitive lives?

Some putative functions of modal judgment might make things easier for us in various ways, and so answer the practical question. But other putative functions might be more closely connected to more significant features of our lives. In particular, we might be interested in whether modal judgment plays any role in our capacity to be thinkers.

Second, there are questions relating to whether we can reduce or even eliminate the modal judgments we need to make.

The Reduction Question Can we reduce the number of legitimate, ineliminable cases of modal judgments?

The Elimination Question Could all modal judgments be refrained from, or replaced with another kind of judgment?

For example, one might think that there is no legitimate, ineliminable function for possibility judgments, but that there is such a function for necessity judgments. Hence, we only need to bear commitments to necessities rather than possibilities. This, in turn, may have interesting consequences for the kinds of commitments we need to incur in our modal metaphysics. For example, suppose one analyses judgments of necessity in terms of universal quantification over worlds, and judgments of possibility in terms of existential quantification over worlds. As universal quantification is not existentially committing, a commitment only to necessity judgments, even analysed in this way, should incur no existential commitment to worlds. ${ }^{6}$ By contrast, one might ask whether the class of modal judgments as a whole could be dispensed with or whether, if they do have a legitimate function, this could be fulfilled by a different kind of judgment. For example, one might take possibility judgments to simply be judgments that something is not known, and necessity judgments to concern what is known or certain.

Finally, there is the kind of modality we are interested in. There are many different kinds of modality. And so we can ask any of these questions for modality in general, or for any specific kind of modality. For example,

The General Question Is there any important function, in any of the above senses, for any judgments of any kind of modality?

The Metaphysical Modality Question Is there any important function, in any of the above senses, for judgments of metaphysical modality?

In this paper, I focus on whether we can find an answer to the transcendental elimination question about metaphysical modality, i.e., what is the transcendental role of metaphysical modal judgment? Would there still be the same kind of thinker, if they refrained from all metaphysical modal judgments?

\footnotetext{
6 This is a very brief and incomplete sketch of the beginnings of Divers's account of agnosticism about possible worlds. See Divers $(2004,2010)$.
} 
One might immediately object: surely most thinkers never make any judgments of metaphysical modality, for metaphysical modality is a philosopher's invention, with little obvious everyday application or use. In which case, the question about the consequences of abstinence from such judgments is close to absurd.

To be clear: there are (at least) two worrisome features of metaphysical modality. First, it is not always terribly clear what, if anything, metaphysical modality is supposed to be, and how we should characterise it. Of course, substantive accounts exist, such as the view that modality has its source in the essences of things. ${ }^{7}$ But this is not helpful as a characterisation of the notion that realists and anti-realists might share and be interested in alike: it already assumes a variety of realism, namely, that modal discourse concerns facts about, or grounded in, essence. It would be interesting if we could find an account of a function for a range of modal judgments that were recognisably "metaphysical", without bearing an antecedent commitment to a realist modal metaphysics. Second, as already noted, one might, quite reasonably, worry that metaphysical modality is an invention of philosophers that doesn't correspond to any real phenomenon that is worthy of proper study. As Williamson remarks,

Does metaphysical modality really matter outside philosophy? Even if physicists care about the physical necessity of the laws they conjecture, does it matter to physics whether physically necessary laws are also metaphysically necessary? In ordinary life, we care whether someone could have done otherwise, whether disaster could have been averted, but the kind of possibility at issue there is far more narrowly circumscribed than metaphysical possibility, by not prescinding from metaphysically contingent initial conditions. He could not have done otherwise because he was in chains, even though it was metaphysically contingent that he was in chains. Does "could have been" ever express metaphysical possibility when used non-philosophically? (2007, p. 135)

If, however, we could find a crucial role for judgments of a kind of modality plausibly classified as metaphysical, this would cement metaphysical modality as an important object of study, not just for the benefit of practising philosophers, but, potentially, for all thinkers. In sum, then, my response to these worries about metaphysical modality is postponed until the end of this paper: if there is an answer to the transcendental question for something that looks for all the world like metaphysical modality, we will have a reason to take it to be more than a philosopher's conceit.

As for my focus on the transcendental question: It strikes me that this is the question at stake if one is interested in the function of modal judgment as potentially underpinning wider theorizing about the metaphysics of modality. For a merely practical use may seem to be too weak. Even if modal judgment had some practical function that committed one to a full dress modal metaphysics, one might worry that such a function may be too contingent a basis for this. In other words, one might worry that a practical function is unlikely to be properly ineliminable, even if legitimate. Even if, say, we cannot do without modal judgments for some practical purpose, the question will always remain whether we can do without fulfilling that practical purpose.

\footnotetext{
7 See, for example, Fine (1994) and Hale (2013).
} 
By contrast, a positive answer to the transcendental question would make a much stronger case for the ineliminability of modal judgment. If being able to make modal judgments is an ineliminable part of our ability even to think about the world, it is harder to dismiss this by claiming that objective thought itself is something we could do without.

One further clarification is in order. There are two broad ways one might give a positive answer to the transcendental question: (1) modal judgment itself directly plays some important role in our cognitive lives; (2) there is some important aspect of our cognitive lives of which the capacity to make modal judgments is a sideeffect, and modal judgment does not, in and of itself, have any further transcendental function. An answer of the first kind would be a straightforwardly positive answer to the transcendental question. In the second case, whilst it would be a valuable result to discover such a source for a capacity for modal judgment, it would be a considerably weaker answer to the same question. Yes, one might say, it is strictly speaking true that modal judgments are a necessary condition of the very possibility of some crucial feature of our cognitive lives, but only because the capacity to make them follows from something else which plays a more explanatory role. In what follows, I attempt to find an answer of the first kind. I want to consider whether modal judgment, if necessary for thinkers like us, is more than a side-effect of more important cognitive capacities.

\section{Suppositions and counterfactual thinking}

There are at least two existing options: accounts of modal judgment based on the importance of a capacity for suppositional reasoning (in, e.g., McFetridge 1990; Divers and Elstein 2012; Divers and González-Varela 2013), and accounts drawing on the importance of a capacity for counterfactual thinking (in, e.g., Williamson 2007; Kroedel 2017).

The former approach originates — at least in its present form in the literature-with McFetridge's argument that our practice of reasoning from suppositions commits us to a belief in logically necessarily truth-preserving rules of inference and, a fortiori, to a belief in logical necessity. The key point of McFetridge's argument is that this practice of reasoning from suppositions commits us to there being some rule of inference that would be valid when reasoning from any supposition whatsoever. In a nutshell: no matter what, this rule holds. Such an approach is not on its own sufficient to answer the metaphysical modality question (and of course, it was not intended to do so). It is presented as an argument to explain the function of beliefs in logical necessity. In more recent work, Divers and others have therefore attempted to develop the proposal to account for belief in absolute necessity, where absolute necessity may turn out to encompass metaphysical necessity.

We contend that some propositions hold with absolute but non-logical necessity, and, as is well known, broadly logical necessity, analytic necessity, mathematical necessity and metaphysical necessity are frequently understood that way. Our central question, then, is whether the McFetridge account of belief in absolute necessity can straightforwardly and successfully encompass the non-logical case(s). (Divers and Elstein 2012, pp. 110-111) 
The strategy begins by distinguishing between two different kinds of supposition on the basis of which one might be reasoning: supposing-as-actual (A-supposition) and supposing-as-counterfactual (C-supposition). A-supposition is associated with expression in the indicative mood as in, for example, 'If Oswald didn't shoot Kennedy, then who did?' Similarly, C-supposition is associated with expression in the subjunctive mood as in, for example, 'If Oswald hadn't shot Kennedy, would someone else have?' In broad terms, a belief in absolute necessity is tied to the practice of C-supposition. Where before a belief in logical necessity was manifested by preparedness to deploy a rule of inference when reasoning from any supposition whatsoever, Divers and González-Varela offer a more complex condition for the manifestation of a belief in absolute necessity.

(MAN) (i) X believes that $\mathrm{P}$ and (ii) for all S, such that $\mathrm{X}$ finds herself [(ii) able to A-suppose $\mathrm{P}$ and (iii) subsequently to $\mathrm{C}$-suppose that $\mathrm{S}$ ] $\mathrm{X}$ is prepared to add $\mathrm{P}$ as a premise in reasoning from the C-supposition that $\mathrm{S}$. (2013, p. 381)

The final clause expresses the idea, similar to that above, that such a belief would be manifested by preparedness to deploy $P$ in reasoning from any supposition whatsoever. Again, in crude terms, $\mathrm{P}$ can be taken to be true no matter what might be the case. The earlier part of the condition adds some constraints on $\mathrm{P}$.

Without examining this proposal in detail, we can already recognise one important feature for present purposes, namely, that the proposal-as an answer to the practical or the transcendental question-stands or falls with the importance of C-supposition in general. As Divers and González-Varela themselves note,

Presuming that $C$-supposition is itself an important (useful, indispensible) activity, one can see how that activity is assisted by our having at our disposal a stock of propositions which-without further ado, independently of (knowledge of) context and without scrutinizing the content of the particular C-supposition in question-we can rely upon (by introducing as premises) in expanding any C-supposition through good inference. Yet, this answer to the question of the function of judgments of absolute necessity is partial in virtue of its presumption, and shifts the question of function to the phenomenon of $C$-supposition itself. (2013, p. 387, emphasis added)

The question then becomes one of the indispensability or otherwise of C-supposition.

There is other work directly addressing the importance of counterfactual thinking. Such work may supplement the Divers project insofar as it proposes explanations of the function of counterfactual thinking. It may also provide its own explanation of the role of modal judgment. The claim is that there is an important role for counterfactual thinking to play in our lives, and that counterfactual thinking is, or involves, or supports, making judgments with modal content.

Williamson presents a version of the counterfactual view that has the potential to answer the transcendental metaphysical modality question. He argues that 'counterfactual thought is deeply integrated into our empirical thought in general' (2007, p. 141); that a cognitive capacity for thinking about metaphysical modality is a by-product of our capacity for thinking about counterfactuals; and hence that a capacity for thinking 
about metaphysical modality is a by-product of a deep-seated feature of our capacity for empirical thought in general.

The epistemology of metaphysical modality requires no dedicated faculty of intuition. It is simply a special case of the epistemology of counterfactual thinking, a kind of thinking tightly integrated with our thinking about the spatio-temporal world. To deny that such thinking ever yields knowledge is to fall into an extravagant skepticism. Here as elsewhere, we can do philosophy on the basis of general cognitive capacities that are in no deep way peculiarly philosophical. (Williamson 2007, p. 178)

The link to metaphysical modality is clear. It is not that we need to make judgments of metaphysical necessity and possibility, but that in being able to make the judgments we do need to be able to make, the capacity for metaphysical modal thinking comes along for free. In short: metaphysical necessity and possibility can be understood in terms of the limiting case of counterfactual thought.

$$
\text { (21) } \square \mathrm{A} \equiv \forall \mathrm{p}(\mathrm{p} \square \rightarrow \mathrm{A})
$$

According to (21), something is necessary if and only if whatever were the case, it would still be the case ... That is a natural way of explaining informally what metaphysical necessity is. (Williamson 2007, p. 159)

I want briefly to raise two concerns for the use of Williamson's view as an answer to the transcendental question. First, whether we can take this to provide an answer to the practical or to the transcendental question, if either, (and also therefore to what extent we can supplement the suppositional approach) depends upon the function of counterfactual thinking. I take Williamson to present four roles for counterfactual thinking: taking something as evidence for something else; learning from the past; planning for the future; and causal thinking (2007, pp. 137-141). One might reasonably take the first three roles to have most potential in the context of an answer to the practical question. Certain kinds of learning and planning are no doubt very useful, but not obviously essential to the very ability to think about the world at all. Perhaps if we lost all three of these abilities, our thinking would be extremely impoverished, but it isn't clear that it would be altogether gone.

From a Kantian perspective, there is something more interesting in the fourth case. For Kant argued that causal thinking is a condition on a capacity for genuine objective thought. How modality gets into the picture may be different-Williamson takes there to be a close link between causal and counterfactual thinking (2007, p. 141), whereas Kant takes the concept of causation to be one of necessary connection ${ }^{8}$ - but in both cases causal thinking is of crucial importance, and is further linked to modal thinking. It is likely that a connection to causal thinking provides one important function for modal thinking. ${ }^{9}$ But that does not stop us from investigating whether there are further, perhaps more direct, functions for modal thinking.

\footnotetext{
8 Kant 1998, 312

9 See Kannisto (2017).
} 
This leads to my second concern with the counterfactual thinking approach, namely, that it only gives the weaker answer to the transcendental question, i.e., the capacity for judgments of metaphysical necessity and possibility follows from an important, ineliminable role for some other kind of thinking, and does not have such a role itself. As noted above, my interest here is in whether we can give the stronger answer.

\section{The Kantian gap}

Let us turn to section 76 of the Critique of Judgment. Kant's argument begins with his distinction between concepts and intuitions. According to Kant, concepts are general representations which, by their nature, can pick out more than one thing (even though they can be used to pick out a single thing sometimes). Concepts also relate mediately to the objects that fall under them, that is, they apply to objects in virtue of features that objects have in common. For example, the concept frog applies to many things, and it applies to them by virtue of features that they have in common. According to Kant, the representations he calls 'intuitions' are singular representations which, by their nature, can only relate to one thing. ${ }^{10}$ Intuitions also relate directly to their objects. One might think of an intuition as a direct presentational relation between a particular and a perceiver. ${ }^{11}$

For Kant, perceivers and thinkers like us need both concepts and intuitionsintuitions to provide a direct link with objects; concepts to conceptualise our presentations of objects as something or other. It is only if both of these capacities co-operate that we can have the kind of experience of the world that is familiar to us. Without concepts, we might be presented with perceptual particulars, but we wouldn't be able to understand or reflect on that experience. For example, I could be perceptually aware, via intuition, of a particular thing, but not be aware that it was a frog. In turn, intuition contributes to the meaning of concepts. One can think of the 'empirical meaning' of a concept as something like: what kinds of things the concept would apply to in the world which is it possible for us to experience. It is only possible for us to experience the world via the contribution of intuition (we need to be presented with objects). Hence, it must be possible for a concept to apply to things given to us in intuition-its purported object(s) must be 'intuitable' - for it to have empirical meaning. This is not to say that concepts that lack empirical meaning are entirely senseless-for example, Kant discusses the 'merely logical significance' that pure concepts have independent of their applicability to objects of possible experience. ${ }^{12}$ I discuss the meaning of concepts and judgments that lack this kind of applicability to objects of experience in more detail elsewhere, but the important point for present purposes is the relation between concepts and intuitions. ${ }^{13}$

\footnotetext{
10 'Singular' doesn't have to mean 'simple'. For example, one might have an intuition that has parts corresponding to the parts of its object. Thank you to an anonymous referee for raising this point.

${ }^{11}$ See Allais (2015).

12 Kant 1998, 276-277

13 Roughly and briefly, the meaning of concepts and judgments that themselves are not intuitable can be derived from (at least) two sources; composition out of concepts and judgments that do have empirical
} 
So, our capacities for intuition and conceptual thought must cooperate. Nevertheless, they are distinct capacities. Hence, they can come apart-we can sometimes have intuitions without concepts, and concepts without intuitions (and so have thoughts that aren't confirmed by direct experience of things being that way). Kant argues that this potential mismatch of two separate capacities means that thinkers like us require the ability to make a distinction between possibility and actuality (and by association, contingency and necessity), because we need to be able to cope with the fact that some of our thoughts do not actually have corresponding intuitions, although they could. We need to possess these modal concepts, in order to make this distinction in thought.

It is absolutely necessary for the human understanding to distinguish between the possibility and the actuality of things. The reason for this lies in the subject and the nature of its cognitive faculties. For if two entirely heterogeneous elements were not required for the exercise of these faculties, understanding for concepts and sensible intuition for objects corresponding to them, then there would be no such distinction (between the possible and the actual).... Thus the distinction of possible from actual things is one that is merely subjectively valid for the human understanding, since we can always have something in our thoughts although it does not exist ... (Kant 2000: 272; 5:401-402)

Note, Kant's concern is more with the one direction - thoughts without intuition - than the other-intuition without concepts - although both are forms of potential mismatch. I take it that this is because the problem for objective representation, developed below, only arises in the former case. Thoughts purport to make some kind of claim about the world that might turn out to be wrong, given the potential lack of intuitive confirmation, whereas intuitions without concepts would amount to a kind of 'uninterpreted' experience. This latter does not so much threaten to lead us into error, as present us with something we might want to learn to conceptualise. ${ }^{14}$

Why do we need to be able to make a distinction between the actual and the non-actual? Given the potential mismatch between intuitions and conceptual thought, suppose we had no means to think about this mismatch. That is, suppose we had no means to think about the difference between those of our thoughts that correspond to or are confirmed by the world and those that don't or aren't. We wouldn't be able to separate thought from reality. This would then threaten our status as objective thinkers. For there would be no way for us to make sense of or acknowledge the difference between how things seem and how things really are.

\footnotetext{
Footnote 13 continued

meaning, or derivation from logical forms. Lack of intuitiability largely comes down to a violation of the conditions of possible experience for which Kant argues. (Leech, ms.).

14 One might also wonder why the representations that potentially lack corresponding intuition have to be conceptual thoughts. Would the same kind of argument run for, for example, a merely imaginative episode? What is important here, is that even an imaginative episode involves the use of concepts-it seems to me very difficult to make sense of completely non-conceptual imagining as something one might engage in. And so, an imaginative episode that lacked a corresponding intuition would be subject to the same general problem: a representation using concepts that lacks suitable intuition. Thank you to an anonymous referee for pressing this issue.
} 
Characterisations of what it takes for a state (say, a thought or judgment) to be objective often require that the state has correctness conditions that are independent of how things are with the subject having the state. Objective states are not subjective. For example, Christopher Peacocke introduces an intuitive notion of minimal objectivity as follows.

A thinker's being in the state, or enjoying the event, does not in general make the content of the state or event correct. (Peacocke, 2009, p. 739)

Anil Gomes defines what he calls a perspectival notion of objectivity in a similar way, but this time the independence is not from the thinker's being in the state, but from the thinker's point of view.

Whether or not something is objective turns on the extent to which it is tied to our point of view; things are objective to the extent that they are independent of a subject's point of view and subjective otherwise. (Gomes, 2016, p. 947)

The thought is then this. Given distinct capacities for thought and intuition, just the thinking of a thought (a thinker's being in that state, say) is not sufficient for the thought to be correct. ${ }^{15}$ That requires that something corresponding to the thought be presented in intuition. Without a distinction between the case where the thought does match up with intuition, and the case where it doesn't, then, we would have no conception of objectivity. We would have no conception that our thoughts might not be correct.

The crucial claim is then: without this conception of objectivity, our ability to have objective thoughts at all would be undermined. One might immediately baulk at this claim. Surely, one might respond, a creature who lacked any conception that some of their representations might be wrong, might still have some states that in some sense match up with the world, and some that don't. Hence, they would have a capacity for objective thought, and merely lack a capacity to recognise their objective thoughts as such. On the contrary: there are good reasons to think that an important role is indeed played by a conception of objectivity.

An important part of objectivity, as it has been understood here, is that objective states might turn out to be wrong, because their correctness conditions concern something beyond the state itself. A question one might naturally ask, then, is how does a state come to have such correctness conditions?

To start, let us consider the case of a barometer. A (working) barometer represents atmospheric pressure; it is correct or incorrect, accurate or inaccurate, depending on whether and how well its states correspond in a predictable way to atmospheric pressure. The correctness conditions, that is, depend on something beyond the state of the barometer itself. However, there is nothing, in and of itself, that makes the barometer represent pressure in this way. Yes, the medium inside the barometer (mercury, say) expands and contracts in proportion to the local atmospheric pressure. But this doesn't, on its own, represent anything-even when expanding and contracting in a tube next to a scale. Of course, the obvious thing to say here is: the barometer represents atmo-

15 There may be trickier cases, for example, the thought that I am thinking something now. This is, I presume, why Peacocke says 'in general'. 
spheric pressure because we take it to. At some point we noticed the relation between volume of medium and atmospheric pressure and exploited it to make devices that represent atmospheric pressure. I think we need to tell a similar story about how our own concepts and thoughts come to have correctness conditions that depend on something beyond the existence of those states themselves. It is because we, in some sense, take them to have these kinds of correctness conditions.

Partly, this is because alternative explanations seem to be inadequate. I take it that a mere causal explanation-that objective states have these correctness conditions due to how the states were caused-is insufficient; there are lots of different potential causes of a representation, not all (if any) of which are the purported object of that representation. Causal chains can be, notoriously, deviant, and so one cannot rely on them to bridge these kinds of gaps. Similarly, one might think that the barometer represents atmospheric pressure because changes in atmospheric pressure cause the different states of the barometer. Well, that latter may be true, but that is still not sufficient for objective representation: we need to take these changes to be representative of pressure. (Compare: after landing in an aeroplane, one might notice that one's water bottle has become squashed, and one might recognise that this was caused by a change in pressure, without taking the shape of the water bottle to represent a change in pressure.)

Here is another route to the same point. It is plausible to think that grasping a thought involves either grasping or knowing or otherwise having some awareness of its truth conditions or satisfaction conditions. ${ }^{16}$ In the case of an objective thought, those satisfaction conditions will concern something beyond the thought itself, as sketched above. On its own, this doesn't entail that we also grasp that these are objective satisfaction conditions. For example, I might grasp what things would have to be like if snow is white, without grasping that things being like that are the satisfaction conditions for the thought that snow is white. However, more generally, a grasp of satisfaction conditions without some kind of conception of satisfaction conditions is too demanding: surprisingly, more demanding than a conception of satisfaction conditions. For, there are cases where grasp of a thought is possible without grasp of its satisfaction conditions, which we may want to accommodate without rejecting our plausible approach wholesale. If one accepts any externalist content at all, then direct grasp of the satisfaction conditions for thoughts including externalist content is far too demanding. For example, one would not be able to have thoughts about gold without grasping satisfaction conditions in terms of atomic number 79. But surely most thinkers can do precisely this. How, then, can we hold onto the plausible idea that understanding involves some grasp of satisfaction conditions, whilst accommodating these difficult cases? Rather than, say, demanding that a thinker grasp that the thought that this nugget of gold is shiny is true just when this nugget of element with atomic number 79 is shiny, a weaker demand would be that a thinker grasp the more general idea that this thought is true or false depending on how things are with things beyond the (thinking of the) thought. Thinkers don't need comprehensive knowledge of external content, but only something more like: whatever thought I'm having, whether it is correct or not does

16 Thank you to Bill Brewer for helpful discussion of this. 
not depend just on my having it, but on something beyond that. As a consequence, just having the thought is not sufficient to make the thought correct; hence, one accesses a distinction between thoughts that are, and are not, correct, given conditions beyond the having of the thought.

It is clear that this sketch needs more flesh on the bones, to spell out more precisely the way we need to grasp correctness conditions, and how that cashes out in different kinds of cases. But I hope the foregoing comments are at least sufficient to lend support to the present point: objective representations have a certain kind of correctness condition, and the best way to explain that they have this kind of correctness condition, is that thinkers who have those representations themselves grasp that they have correctness conditions that depend on something other than the (thinking of the) representation itself. ${ }^{17}$

These remarks may be reminiscent of Hannah Ginsborg's work on the normativity of meaning (of concepts and of language). Ginsborg contrasts a view according to which meaningful things have correctness conditions, but thinkers do not need to have a grasp of the idea of correctness conditions, with her own view where some additional awareness of correctness conditions is required (Ginsborg 2012). She develops Wittgenstein's story of the builders: when the builder shouts 'Slab!' the assistant responds by passing over a slab, and when the assistant looks under the tarp and sees a slab, he utters 'Slab'. Ginsborg argues that a dispositional story does not adequately account for the meaningfulness of these utterances.

[T] he dispositionalist account fails to accommodate the idea that meaning, in the relevant sense, requires understanding. The reason why the automaton and the hypnotized agent, fail to mean anything by 'slab' is that they fail to understand 'slab'. They respond to it, so to speak, blindly, or, as Kripke puts it, in a 'jackin-the-box' way (1982, p. 23). But in order for users of an expression to mean something by an expression, or for the expression itself to mean something in the semantic sense rather than the sense of indicating, the expression must be understood by its users. (Ginsborg 2012, p. 134)

According to Ginsborg, in addition to having the right responses, the assistant must be taking his responses to be appropriate to the situation, that is, he must be taking some explicitly normative attitude.

My sketch of a view diverges from Ginsborg in important ways. But we share the core idea that thinking or saying something with meaning and understanding requires more than the thought or expression having correctness conditions; the thinker or speaker must also have a certain kind of awareness or grasp of those conditions as correctness conditions. Ginsborg cashes things out in terms of a certain kind of normative attitude: taking one's utterance to be fitting or appropriate. My proposal is

\footnotetext{
17 Another option, not explored here, but accepting the main premises, would be that others take the representation to have the appropriate correctness conditions, i.e., some appeal to a community explanation. But still, that would require at least some members of the community to have a conception of objectivity. And it would seem a sorry and unequal state of things if only a privileged few had that conception, and thereby conferred objectivity on the representations of the masses. So even on this alternative, it would make better sense if the majority of, if not all, thinkers have a conception of objectivity.
} 
slightly different, but in a similar spirit: taking one's thought to depend on how things are beyond (the having of) that thought for its correctness.

One final clarification: this sketch of an argument concerns concept-involving representations, primarily, thoughts and judgments. Nothing I have said, at least on the face of it, requires one to make any claim either way concerning whether we could have any states relating to objects at all without a conception of objectivity. ${ }^{18}$ Perhaps there is still some basic perceptual relation to objects that intuition provides us with, for example. But it seems plausible that something more sophisticated-objective thoughts-would have more demanding conditions. ${ }^{19}$

Let us now grant that some conception of correctness conditions for a thought that do not depend upon the (thinking of the) thought is required for one to have objective thoughts. What is the link to the actual/non-actual distinction? One might think that it is enough to have the concept of a thought's satisfying these conditions (something like a concept of the actual) without also requiring the concept of a thought's failing to satisfy these conditions (something like a concept of the non-actual). ${ }^{20}$ For then we would still grasp the fact that the thought depends upon something other than (the thinking of it) itself. However, it seems to me that once one has the idea that a state is correct only when certain conditions independent of the state obtain, that just does include the idea that, should those conditions not obtain, then the state will not be correct. Without this other-negative-side, we would just have the idea that these states relate to the world in an important way. But that wouldn't give us the resources to cope with the fact that some of these states do not match up with how the world is; that was the starting point of Kant's argument, after all. Something like this line of thought can be found in Davidson's argument for the related thesis that in order to be able to have beliefs one must have a concept of belief, that proceeds via the idea that one must be capable of surprise, where surprise involves a belief that one's prior belief was false.

Surprise requires that I be aware of a contrast between what I did believe and what I come to believe. Such awareness, however, is a belief about a belief: if I am surprised, then among other things I come to belief my original belief was false. I do not need to insist that every case of surprise involves a belief that a prior belief was false (though I am inclined to think so). What I do want to claim is that one cannot have a general stock of beliefs of the sort necessary for having any beliefs at all without being subject to surprises that involve beliefs about the correctness of one's own beliefs. (Davidson 1982, p. 326)

\footnotetext{
18 I don't intend to take on Tyler Burge's claims about perceptual objectivity here (Burge 2010).

19 A different approach to understanding objectivity puts things in terms of the possibility of faultless disagreement, rather than correctness conditions. For example, in his classic treatment, Crispin Wright (1992) argues that one can make sense of minimal truth-aptness even for non-objective areas of discourse, and that the question of objectivity (or realism) relates to whether more substantive conditions hold for the area of discourse. I will continue to put things in terms of correctness conditions, but I believe that the same points could be recast in these different terms. One could understand the potential mismatch between thought and intuition that Kant highlights as corresponding to the idea that, in a case of objective thought, disagreement absent cognitive shortcomings and errors could be explained by a difference in input.

20 Thank you to an anonymous referee for pressing this point.
} 
Belief or thought about correctness of beliefs or thoughts just does encompass the possibility of discovering or thinking that a belief or thought is false, and hence requires the conceptual capacity to think of the difference between the actual and the non-actual.

So, a distinction between actual and non-actual is required for objective thought. With this in place, why do we (also) need to be able to make a conceptual distinction between the possible and the actual? The remainder of this paper will be devoted to an attempt to answer this question.

I offered one kind of answer to this question in Leech (2014). My proposal was that this distinction is required to support our epistemic projects. Suppose we have identified a class of thoughts that are not (yet) confirmed by experience. If we want to gain more knowledge about the world, it would be helpful if we could isolate, from amongst these, those thoughts that are at least possibly true. For then we can direct our epistemic endeavours upon those cases, and not waste time on investigating the impossible. The main problem with this proposal, given present purposes, is that it provides an answer, if any, to the practical rather than the transcendental question. We would most likely still get somewhere in our epistemic projects if we just sought out confirmation of our non-actual thoughts; the impossible ones might simply slow us down.

\section{Another Kantian gap}

We need to think again about the requirement underpinning objective thinking that was supposed to have been met by the actual/non-actual distinction. This was the connection between objectivity and idea that, in general, a state has correctness conditions independent of the subject being in that the state, or something similar. ${ }^{21}$ The importance of a distinction between the actual and the non-actual was a consequence of the fact that those correctness conditions might be met or not independent of the subject being in that state. Typically, this is taken to be the condition of objectivity, and states are taken to be subjective otherwise (as is made explicit in the Gomes quotation above). However, an important feature of Kant's thinking on objectivity that is often overlooked is that there are two very different ways in which a thought might fail to be objective. It might be subjective, as in, its correctness conditions do depend on the subject being in that state in some way (for example, whether the state is correct depends on the existence of the state, or on the point of view of the subject of that state). However, it might fail to have either of these kinds of correctness conditions - those that depend on how things are with the world, and those that depend on how things are with the subject or state. To put things the other way around, there are two importantly different ways that a thinker's being in a state does not make the content of the state correct: because the correctness conditions depend upon the world; because if the state has correctness conditions at all, they aren't set by the world or by the (subject being in that) state. Similarly, there are two different ways that something

\footnotetext{
21 Again, there are tricky cases, e.g. the thought that I am thinking. However, such cases may lend support to the view developed here that we need more resources than these to have a proper conception of objectivity.
} 
might be independent of a subject's point of view: it depends on how the world is; it doesn't depend either on how the world is, or on how the subject is.

In short, an objective thought depends for its correctness on how things are with the world. A subjective thought depends for its correctness on how things are with the representation itself and/or the perspective of the subject of the thought. But there is nothing - thus far - that requires that a thought be either objective or subjective. It might fail to have correctness conditions. Or it might have much thinner correctness conditions, for example, mere logical conditions that concern a thought's consistency, but which do not go so far as to determine whether it gets the world (or the subject) right or wrong. I prefer this latter. In Leech (2015) I argue that the laws of logic are constitutive norms for thought, i.e., that a state must be evaluable in light of the laws of logic if it is to count as a thought. If this is right, then all thoughts are subject to some (logical) correctness conditions. But these are different to the further correctness conditions that objective and subjective thoughts have as well. One might disagree with this kind of view, but for present purposes the question of the exact status of non-objective non-subjective thoughts can be left open. The main point is that there is a third option. ${ }^{22}$

Bringing this back to the question at hand: it was proposed that we could understand the function of an ability to make judgments about the actual and the non-actual as a requirement of objective thought. But that was based on an understanding of objectivity according to which the distinction between the objective and the subjective is exhaustive. On this assumption, a conception of correctness conditions that are not subjective - that is, that do not depend on (the thinker having) that thought-would just be a conception of objective correctness conditions. However, if one follows Kant in rejecting this assumption, and accepts that there are three options here, then one needs to make a further distinction. If we want to be able to grasp the idea of a thought with correctness conditions that don't just not depend upon the thought, but also depend upon the world, we need to distinguish this from the case where a thought has neither of these kinds of correctness conditions. That is, amongst the thoughts that do not depend upon the state-those which we can distinguish by using the actual/non-actual distinction — we need to be able to distinguish those that have correctness conditions that depend upon the world and those that do not. The proposal is that it is the additional distinction between the impossible and the possible that allows us to do this. Objective thoughts could be rendered correct by the world, even if they are actually not. ${ }^{23}$ Non-objective, non-subjective thoughts could not be rendered

\footnotetext{
22 Again, the same point could be recast in terms of faultless disagreement. Even if we agree that objectivity is a matter of there being no possibility of faultless disagreement, we might still recognise that there are at least two very different ways that faultless disagreement might be possible: because the discourse is after all tied to some kind of opinion or reaction that relates to the subject in an important way, such as finding something funny or delicious; or because the discourse has no further correctness conditions beyond the standards of assertibility that are required for the discourse to be minimally truth-apt (putting matters in Wright's terms), and those standards of assertibility are suitably thin to seem different to canonical subjective matters, for example, statements ought to be non-contradictory, but appear to have no relation at all to a subject's perspective or opinion.

23 This may appear to smuggle in the kind of realism about modality that I specified earlier should be left open. However, whilst the conception of possibility at work here is one that concerns a possible relation between a thought and the world, it does not build in a particular view about which thoughts are possible
} 
correct by the world because they do not even go so far as to be about the world. They only have thin, logical standards of correctness, if any.

Take, for example, my thought of a pink frog on my desk. Not only is it non-actual, it is possible. A pink frog could have been on my desk, but one is not. But this means that it makes sense to think of it as false of the world, as failing to live up to its correctness conditions. This would be different to my thought (examples are difficult, so let's go with Kant) that I had a conversation with God yesterday. Such a thought just isn't the right kind of thing to be confirmed by experience, and so doesn't have the right kind of correctness conditions to be objective. ${ }^{24}$

We thus need to revise the conception of objectivity canvassed above. Objectivity is not just a matter of having non-subjective correctness conditions, but also of being possible. A thought is thus objective, then, only if we take it to have objective correctness conditions, and if it is possible. Possibility is implicated in a proper conception of objective correctness conditions, hence, this requires us to also have a concept of possibility.

To sum up, the "Kantian gap" approach puts forth the idea that an ability to make modal judgments using modal concepts such as possible and its cognates has an ineliminable role to play in the possibility of objective thought. The proposal rests on several key assumptions: that creatures with minds like ours have two separate capacities for direct presentation of objects (intuitions) and for conceptual thinking; that there are two ways for a thought to fail to be objective; that the objectivity of a representation requires that the subject having the representation have some conception of objectivity; that modal concepts are implicated in this conception of objectivity (for reasons connected to the second assumption). These together, I have argued, combine to form a case for the importance of a distinction between the possible and the actual as underpinning our status as objective thinkers. Hence, the proposal promises to answer the transcendental question.

To return briefly to Kant: in the sections of the Critique of Judgment that have inspired this line of thought, Kant contrasts our kind of cognitive capacities-involving two distinct capacities for intuition and for thought-with those of an 'intuitive understanding', who has one single capacity for both intuition and thought. Kant argues that creatures like us, with that split cognitive architecture, require modal concepts, but that the intuitive understanding would not.

\section{Footnote 23 continued}

or not, and what kind of account of that possibility we should give. More detail on this conception of possibility - beyond reasons to take it to be metaphysical - is a task for another time.

24 If objectivity and possibility are thereby closely tied, one might wonder about interactions with negation. For, in the case of necessities and impossibilities, it would seem that one could transform an objective to a non-objective thought, and vice versa, with the mere addition of negation. This would be bizarre indeed, if objectivity corresponded to meaningfulness. For it would be absurd to claim that, for example, whilst $2+$ $2=4$ is necessarily true and objective, it is not the case that $2+2=4$ is suddenly meaningless. It would be even more absurd to claim that whilst $2+2=5$ were impossible and meaningless, as if by magic, it is not the case that $2+2=5$ is meaningful (and, indeed, necessarily true). But this is not the intended view. It is more plausible that, if a thought isn't the kind of thought that could make a claim that is right or wrong depending on how the world is, then the world couldn't be that way, for if it could, then the world's being that way would presumably be the correctness conditions for the thought. But if the world therefore isn't that way, it can surely be possible to have the objective thought that it isn't. Thank you to an audience member at the University of Stirling for raising this question. 
I cannot presuppose that in every [cognitive] being thinking and intuiting, hence the possibility and actuality of things, are two different conditions for the exercise of its cognitive faculties. For an understanding to which this distinction did not apply, all objects that I cognize would be (exist), and the possibility of some that did not exist, i.e. their contingency if they did exist, as well as the necessity that is to be distinguished from that, would not enter into the representation of such a being at all. (Kant 2000: 273; CJ 5: 402-3)

Details of this argument aside, our present question is: if the above argument is successful, that the ability to make a distinction between the possible and the actual is a condition of objective representation, then is Kant committed to the view that the intuitive understanding is incapable of objective representation ${ }^{25}$ Given that the intuitive understanding is supposed to be 'divine', and so potentially a way to think of what God's mind might be like, surely the conclusion that God can't represent the world is unacceptable. Luckily, Kant is not so committed. It is important to remember that the argument is intended to apply to 'creatures like us', that is, thinkers that have the potential to be mistaken. In particular, for Kant, we can be mistaken because objective thought requires the cooperation of two capacities that have the potential to come apart. In the case of the intuitive understanding, there is no potential for error, for to think of something is at the same time to intuit it, so there is no possibility of thought without a corresponding object. The conditions of objective representation for the intuitive understanding will be very different.

\section{The metaphysical modality question}

There remains the question of whether this proposal can answer the metaphysical modality question. What is the content of the modal concepts that would play the role outlined above? And what would it take for that to count as metaphysical? The possibility in question concerns the possibility of being given an object, but not much more than that, that is, it does not include constraints connected to the laws of nature, or the behaviour of actual kinds, but rather the most general conditions of thoughts being able to be presented with corresponding objects. Metaphysical modality is often characterised as absolute, where this means that if something is absolutely necessary, then there is no (alethic, non-epistemic) sense of possibility according to which it might have been otherwise, and that if something is absolutely possible, if it is possible in any (alethic, non-epistemic) sense, it is possible in this sense. ${ }^{26}$ However, logical modality might also seem to be absolute in this sense. But metaphysical modality is intended to be distinct from logical modality. Loosely speaking, metaphysical modality has something extra to do with being. Gideon Rosen puts this in terms of metaphysical modality being a real modality. Combining these thoughts, we should expect metaphysical modality to be the most absolute of the real modalities, the modalities concerned with being. Indeed, this is essentially Rosen's characterisation.

\footnotetext{
25 Thank you to an anonymous referee for raising this question.

26 See, for example, Hale (1996).
} 
If $\mathrm{P}$ is metaphysically necessary, it is necessary in every real sense: If $\mathrm{P}$ is really possible in any sense, then it's possible in the metaphysical sense. (Rosen 2006, p. 16)

With this in mind, I would suggest that the modality implicated by the "Kantian gap" argument deserves the title of "metaphysical modality", because it concerns the most general conditions under which an object could be given.

One consequence of drawing this connection between the modal concepts implicated in objective thought above and the notion of metaphysical modality, is that it might seem to rule out the possibility of objective thought about impossibilities. One might take this to raise a significant problem for the accommodation of a posteriori metaphysical necessities. ${ }^{27}$ If it really is a posteriori, for example, that Socrates is human, or that water is $\mathrm{H}_{2} \mathrm{O}$, then it had better not be unthinkable that Socrates is not human (e.g., that Socrates is a robot), or that water is not $\mathrm{H}_{2} \mathrm{O}$ (e.g., that water is an element). However, it is important to remember that, on the proposed view, there are non-objective (non-subjective) thoughts. It is not unthinkable that Socrates is a robot, or that water is an element, even of it is not possible to think these objectively. And it may well take significant empirical work to discover that a thought that seemed to be objective is, after all, not, because it is impossible, just as it may take significant empirical work to discover that a thought is necessary, or impossible. As long as the impossibilities are meaningful and thinkable, as is allowed, then we can't take a short cut from unthinkability to impossibility.

In conclusion, there are several different questions we might be asking when we ask: 'what is the function of modal judgment?'. Some particularly interesting questions concern the transcendental role of modal judgment, and the transcendental role of peculiarly metaphysical modal judgment. I have argued that the "Kantian gap" approach promises direct answers to the transcendental metaphysical modality question. But, it turns out, that promise depends on not one, but two, Kantian gaps. The first is the potential mismatch between concepts and thoughts, on the one hand, and intuitions, on the other. The second is a gap that Kant saw between objective and subjective representations. The proposal is, then, that in order for objective thought to be possible in the light of these two gaps, thinkers require an ability to conceptually distinguish between the possible and the actual, and hence require an ability to apply modal concepts, and make modal judgments. If I am right that there is good reason to call the kind of modality implicated in these concepts "metaphysical", then we also have a potential answer to the transcendental metaphysical modality question. ${ }^{28}$

Open Access This article is distributed under the terms of the Creative Commons Attribution 4.0 International License (http://creativecommons.org/licenses/by/4.0/), which permits unrestricted use, distribution, and reproduction in any medium, provided you give appropriate credit to the original author(s) and the source, provide a link to the Creative Commons license, and indicate if changes were made.

\footnotetext{
27 As an anonymous referee did.

28 Many thanks go to audiences in Frankfurt and Stirling for helpful responses to the paper, as well as to John Divers and Bill Brewer for discussion of some of the philosophical issues. Thank you also to two anonymous referees for this journal, who offered insightful and constructive comments.
} 


\section{References}

Allais, L. (2015). Manifest reality: Kant's idealism and his realism. Oxford: Oxford University Press. Blackburn, S. (1993). Morals and modals. In Essays in quasi-realism. Oxford: Oxford University Press. Burge, T. (2010). Origins of objectivity. Oxford: Oxford University Press.

Davidson, D. (1982). Rational animals. Dialectica, 36(4), 317-327.

Divers, J. (2004). Agnosticism about other worlds: A new antirealist programme in modality. Philosophy and Phenomenological Research, 69(3), 660-685.

Divers, J. (2010). Modal commitments. In B. Hale \& A. Hoffmann (Eds.), Modality: Metaphysics, logic, and epistemology. Oxford: Oxford University Press.

Divers, J., \& Elstein, D. (2012). Manifesting belief in absolute necessity. Philosophical Studies, 158(1), $109-130$.

Divers, J., \& González-Varela, J. E. (2013). Belief in absolute necessity. Philosophy and Phenomenological Research, LXXXVII(2), 358-391.

Fine, K. (1994). Essence and modality. Philosophical Perspectives, 8, 1-16.

Ginsborg, H. (2012). Meaning, understanding and normativity. Proceedings of the Aristotelian Society Supplementary, LXXXVI, 127-146.

Gomes, A. (2016). Unity, objectivity, and the passivity of experience. European Journal of Philosophy, 24, 946-969.

Hale, B. (1996). Absolute necessities. Philosophical Perspectives, 10, 93-117.

Hale, B. (2013). Necessary beings: An essay on ontology, modality, and the relations between them. Oxford: Oxford University Press.

Kannisto, T. (2017). Kant on the necessity of causal relations. Kant Studien, 108(4), 495-516.

Kant, I. (1998) Critique of pure reason. Translated and edited by Paul Guyer and Allen W. Wood. New York: Cambridge University Press.

Kant, I. (2000) Critique of the Power of Judgement. Ed. P. Guyer trans. P. Guyer and E. Matthews. Cambridge: Cambridge University Press.

Kroedel, T. (2017). Modal knowledge, evolution, and counterfactuals. In R. W. Fischer \& F. Leon (Eds.), Modal epistemology after rationalism (Vol. 378). Berlin: Synthese Library.

Leech, J. (2014). Making modal distinctions: Kant on the possible, the actual, and the intuitive understanding. Kantian Review, 19(3), 339-365.

Leech, J. (2015). Logic and the laws of thought. Philosophers' Imprint, 15(12), 1-27.

Leech, J. ms. The significance of Kant's mere thoughts.

McFetridge, I. (1990). Logical necessity: Some issues. In J. Haldane \& R. Scruton (Eds.), Logical necessity and other essays. London: Aristotelian Society.

Nolan, D. (2010). Response to John Divers. In B. Hale \& A. Hoffmann (Eds.), Modality: Metaphysics, logic, and epistemology. Oxford: Oxford University Press.

Peacocke, C. (2009). Objectivity. Mind, 118, 739-769.

Rosen, G. (2006). The Limits of Contingency. In F. MacBride (Ed.), Identity and modality, mind association occasional series (Vol. 13-39). Oxford: Oxford University Press.

Williamson, T. (2007). The philosophy of philosophy. Oxford: Blackwell.

Wright, C. (1992). Truth and objectivity. Cambridge: Harvard University Press. 